\title{
Operators' attitudes on educational tourism in agriculture
}

\author{
Y. Ohe \\ Department of Food and Resource Economics, Chiba University, Japan
}

\begin{abstract}
This paper focused on the educational function in agriculture in relation to educational tourism in agriculture. An understanding of the educational function of agriculture can provide evidence to support educational tourism in agriculture, which is now attracting growing attention. This attention is an outgrowth of the rapid change in modern society that has taken people away from their traditional connections with their agrarian heritage and food production. Despite the mounting expectations with regard to the educational function of agriculture, this function has not been fully explored empirically. The author considers this educational function as a new role that agriculture can play in society in addition to the traditional role of food production; therefore it should be clarified from an empirical aspect. First, as a demand side examination, we briefly characterized the educational tourism conducted in elementary and junior high schools in Japan by focusing on school trip programs. Second, as a supply-side examination, this paper examined empirically how the educational function has been practiced in Japan by focusing on the Educational Dairy Farm program. Results of a questionnaire survey conducted by the author showed that operators of the Educational Dairy Farms gained satisfaction from their educational activities that allowed children and urbanites to learn of the close connection between food and life, which is often forgotten in the busy modern society. Further, the educational function in agriculture provides opportunities not only for visitors, but also for the operators themselves to experience this new role of agriculture with a sense of satisfaction and local pride. Nevertheless, these educational services have not yet become economically viable. Therefore, cohesive local support measures should be taken to raise social recognition of educational tourism in agriculture.

Keywords: educational tourism, educational function in agriculture, school trip, Educational Dairy Farm, farm experience services.
\end{abstract}




\section{Introduction}

The educational function in agriculture, which provides the structure for educational tourism in agriculture, is attracting growing attention not only in developed countries, but also in developing countries. This is because geographical and psychological distances between rural and urban lives have increased rather than decreased despite rapid progress in transportation and information technology. Loss of traditional healthy dietary habits is one of the issues of this phenomenon. To counter this issue, first-hand experiences of farm and rural life provide recreational opportunities and also opportunities to learn what cannot be experienced in urban life such as where food comes from and what rural life and heritage are despite the fact that these things are deeply connected with the cultural identity of urban inhabitants but are often forgotten in busy modern life. On the other hand, the educational function gives farmers a new social role and a new income opportunity in the face of stagnant prices for farm products. While the demand for educational services provided by farmers is increasing steadily as conducted as a part of school curriculum, the educational function has not been investigated fully.

Conventionally, it has been 'city farms' that typically provide educational services to youngsters through farming and rural experiences (Garrett [1]). 'City farms' have a similarity to educational farms and the definition of educational farms differs from one country to another. From my understanding, 'city farms' pay more attention to educational aspects while on educational farms, for instance, in Japan, activity is based on farm production rather than educational services, with educational services being provided as supplementary services. Recently, public programs that strengthen the connection between the educational aspects of farming and the countryside are emerging in Europe and Japan. Examples are the FACE (farming and countryside education) program in UK (Graham [2]), Ferme Pédagogique in France, Fattorie Didattiche in EmiliaRomagna (Regione Emilia-Romagna [3]) in Italy and Educational Dairy Farms in Japan (Ohe [4-6]).

Thus, firstly, we briefly characterize educational tourism conducted by elementary and junior high schools in Japan by focusing on school trip programs as a demand-side examination. Secondly, we investigate the significance and problems related to the educational function in agriculture by focusing on activities conducted by farmers associated with the group Educational Dairy Farms, which provides educational farm experience services to school children and families in Japan and is organized under the Japan Dairy Council. Data were obtained from a questionnaire survey of member farmers of Educational Dairy Farms conducted by the author in 2009. Finally, we present policy recommendations for the sustainable and viable development of the educational function and tourism in agriculture. 


\section{Educational tourism in Japan}

Educational tourism has significance in that it allows children to have a brief experience in various ways of life. Here, we examine the current situation of educational tourism by focusing on school trips that are implemented as a part of school curriculum in Japan. Provision of school trips has been practiced widely not only in obligatory educational institutioni.e. elementary and junior high schools, but also in high schools: $88.6 \%$ of elementary, $94.4 \%$ of junior high and $81.8 \%$ of high schools provide such trips.

Data on trips abroad were not included among this information (Databook Annual Report on School Trips 2009). Generally, a school trip is implemented in the year of graduation or the year before. Because of this high ratio of implementation of trips among schools and the consistent annual demand for school trips, which are not seriously affected by economic fluctuations, such trips hold appeal as a lucrative market for tourism enterprises. It is necessary that local communities have lodging facilities of sufficient size to accommodate a large number of visitors, including large groups of students. Otherwise, a local community must have a lodging system that provides accommodation by dividing visitors into small groups. Generally, Japanese style hotels can flexibly accommodate groups of various sizes because such hotels use 'futon', sleeping mats that are portable and foldable, instead of beds. For these reasons, as shown in Table 1, data from 2008 showed that $50 \%$ of elementary schools lodged their students in Japanese style hotels, 'ryokan', followed by $40 \%$ in western style hotels, whereas only $1.2 \%$ of schools used farmhouse accommodation.

Table 1: $\quad$ Lodging facilities used for school trips.

\begin{tabular}{|c|c|c|c|c|}
\hline School & \multicolumn{2}{|c|}{ Elementary school } & \multicolumn{2}{c|}{ Jr. high school } \\
\hline Lodging facility & $\begin{array}{c}\text { No. } \\
\text { respondents }\end{array}$ & $\%$ & No. stays & $\%$ \\
\hline Hotel (western style) & 223 & 38.6 & 1326 & 55.0 \\
\hline Japanese ryokan (Japanese style) & 284 & 49.2 & 857 & 35.6 \\
\hline Public facility & 14 & 2.4 & 18 & 0.7 \\
\hline Public lodging facility (Kokumin-syukusya) & 17 & 2.9 & 3 & 0.1 \\
\hline Holiday village & 6 & 1.0 & 1 & 0.1 \\
\hline Public youth hostel & 11 & 1.9 & 7 & 0.3 \\
\hline Inn & 10 & 1.7 & 21 & 0.9 \\
\hline Farmhouse accommodation & 7 & 1.2 & 31 & 1.3 \\
\hline Pension & 1 & 0.2 & 64 & 2.7 \\
\hline Others & 5 & 0.9 & 80 & 3.3 \\
\hline Total & 578 & 100.0 & 2408 & 100.0 \\
\hline
\end{tabular}

Source: Databook Annual Report on School Trips 2009 issued by The Japan School Tours Bureau. Data were surveyed as of 2008 . 
Likewise, in the case of junior high schools, hotels accounted for more than half of stays (55\%) followed by 'ryokan' (35.6\%), while use of farmhouse accommodation was negligible (1.2\%).

There are two peak seasons for school trips (Table 2). Elementary schools conducted their trips most frequently in autumn and early winter, that is, from October to November (41.4\%), followed by spring and early summer, from May to June (37.5\%). As shown in Table 2, by far the most frequent duration was two days, which included a one-night stay $(78.5 \%)$ The destination was firstly Kyoto, secondly Mie, and thirdly Nara, all of which have sites of historical heritage. Average travel expense was 25.7 thousand yen. Naturally, transportation and accommodation costs constituted the two major expenses, $35.4 \%$ and $37.6 \%$, respectively, while $10.5 \%$ of the cost was for learning related to the experience such as fees and materials needed for experience services (Table 2).

Table 2: $\quad$ Months and duration of school trips.

\begin{tabular}{|c|c|c|c|}
\hline \multicolumn{2}{|r|}{ Item } & $\begin{array}{l}\text { Elementary } \\
\text { school (\%) }\end{array}$ & $\begin{array}{c}\text { Jr. high school } \\
(\%)\end{array}$ \\
\hline \multirow{5}{*}{ Month } & April & 7.3 & 18.0 \\
\hline & May & 21.5 & 39.9 \\
\hline & June & 14.8 & 17.0 \\
\hline & October & 31.7 & 4.3 \\
\hline & November & 11.4 & 4.9 \\
\hline \multirow{2}{*}{$\begin{array}{l}\text { Duration of } \\
\text { trip }\end{array}$} & 2 days & 78.5 & 75.0 \\
\hline & 3 days & 16.4 & 23.0 \\
\hline \multirow{4}{*}{$\begin{array}{l}\text { Major travel } \\
\text { cost items }\end{array}$} & Transportation & $9,106(35.4)$ & $26,332(42.6)$ \\
\hline & Accommodation & $9,656(37.6)$ & $20,511(33.2)$ \\
\hline & Experience learning & $2,710(10.5)$ & $4,086(6.6)$ \\
\hline & Average total expense & $25,704(100.0)$ & $61,744(100.0)$ \\
\hline
\end{tabular}

Source: Data are the same as for Table 1. Note: Data on the duration of trip for Jr. high school were based on the 2007 survey bacause the 2008 survey did not include that data.

In the case of junior high schools, school trips were implemented mostly from April to May $(74.9 \%)$ while less than $10 \%$ were taken from October to November (Table 2). Thus, school trips in junior high school are undertaken earlier in the school year than those in elementary schools. This is because students need to prepare for high school entrance exams in the winter of the graduation year. The portion of three-day trips increased and the destinations were farther compared with elementary school trips, so that travel expense increased $(61,774$ yen). Transportation cost accounted for more than $40 \%$ of the total cost, followed by accommodation cost at $33.2 \%$. Although the total experience learning cost, at 4.5 thousand yen, was greater than that for elementary schools, the percentage $(6.6 \%)$ of the total cost was lower. The top 
three destinations were Kyoto, Tokyo and Nara. Kyoto and Nara were often combined as an excursion to ancient capitals.

Table 3 shows how experience learning programs were implemented in school trips. Although the ratio of implementation of experience learning in elementary schools did not distinctly increase over the period examined, overall, nearly $50 \%$ of schools implemented experience learning. In contrast, the ratio of implementation of experience learning increased greatly among junior high schools during the same time period; beginning in 2005 more $60 \%$ of schools conducted such programs. Programs undertaken were diverse, and popular programs for elementary schools were pottery experience, experience in traditional crafts, and cooking experience: $23.5 \%, 15.2 \%$ and $14.6 \%$, respectively. Programs for rural experience accounted for merely $9.6 \%$. Likewise, junior high schools had a similar tendency in providing a rural experience $(6.2 \%)$ but sports experience accounted for $15 \%$ of programs. Thus, rural experience programs were not widely offered although farm and rural experience programs played a certain role in school trips. As a measure of rural revitalization, many local communities now try to accommodate school trip programs. On the farm side, since the Educational Dairy Farms have provided the earliest and most organized educational activity, the author examines operators' attitudes on that educational activity below.

Table 3: Implementation ratio of experience learning.

\begin{tabular}{|c|c|c|}
\hline Year & Elementary school (\%) & Jr. high school (\%) \\
\hline 1986 & - & 17.1 \\
\hline 1992 & 33.6 & - \\
\hline 1996 & 35.0 & - \\
\hline 1998 & - & 28.1 \\
\hline 2000 & 46.1 & 37.8 \\
\hline 2004 & 31.8 & 50.6 \\
\hline 2005 & 60.5 & 63.3 \\
\hline 2006 & 45.7 & 62.1 \\
\hline 2007 & 48.5 & 63.0 \\
\hline 2008 & 49.6 & 63.7 \\
\hline
\end{tabular}

Source: Data are the same as for Table 1.

\section{Educational dairy farms in Japan}

\subsection{Outline of the program of educational dairy farms}

The program Educational Dairy Farms was established in 2000 by the Japan Dairy Council, which is a national organization for dairy farmers. The purpose of this program is to provide accurate information on what dairy farms do to improve the public's understanding of the role of dairy farming in society. The Educational Dairy Farms' aim is not only to promote an open-door policy for the 
farmyard toward the outside, but also to enhance the educational value of dairy farming through teaching where milk comes from and the life of the milk cows on the farm. For instance, when visitors have a milking experience, they learn that warm milk comes from the udder of a cow, which is a simple fact, but is quite different from the cool milk in a carton in the refrigerator that they are used to drinking every day. If they are lucky enough, they can witness the birth of a calf, which makes a lifetime impression on children or even adults by evoking the meaning of life. People learn what food is and the close connection between food and life from these experiences. In this respect, farmers' role is crucial and thus they are called facilitators in this program.

To be a facilitator on Educational Dairy Farms, a farmer or an employee must attend a course on principles, safety and hygiene, and on communication skills as well as presentation of a case study provided by the Council. The Council administers the certification for recognition as an Educational Dairy Farm and presents various capacity building courses for those with certification as an Educational Dairy Farm as well as dairy farmers at large in Japan. When my survey was conducted in 2009, there were 257 membership farms.

The number of visitors to Educational Dairy Farms increased yearly to reach more than 880 thousand in 2009 (Table 4). This represents a 3.89 times increase from 2003, which is far greater than the increase in the number of the Educational Dairy Farms, which was 1.5 during the same period. As a consequence, the number of visitors per farm increased from 1,353 to 3,421 , an increase of 2.53 times. This suggests that the demand for farm experiences has steadily grown to a level that can form a market or at least to a level that has the potential to become a market. I assume that this mounting demand presents an opportunity for a new social role that dairy farmers can play in society.

Table 4: Trend of no. of visitors and no. of Educational Dairy Farms (EDFs).

\begin{tabular}{|c|c|c|c|c|c|c|c|}
\hline Year & $\begin{array}{c}\text { First period } \\
\text { (April-September) }\end{array}$ & $\begin{array}{l}\text { Second period } \\
\text { (October-March) }\end{array}$ & $\begin{array}{l}\% \text { share of } \\
\text { first period }\end{array}$ & Total & $\begin{array}{l}\text { Ratio for } \\
\text { each year }\end{array}$ & $\begin{array}{l}\text { No. } \\
\text { EDFs }\end{array}$ & $\begin{array}{c}\text { No. visitors } \\
\text { per farm }\end{array}$ \\
\hline 2003 & 162,484 & 63,392 & 71.9 & 225,876 & 1.00 & 167 & 1,353 \\
\hline 2004 & 254,542 & 89,600 & 74.0 & 344,142 & 1.52 & 174 & 1,978 \\
\hline 2005 & \multicolumn{5}{|c|}{ No data } & 183 & - \\
\hline 2006 & 421,855 & 133,285 & 76.0 & 555,140 & 2.46 & 200 & 2,776 \\
\hline 2007 & 465,593 & 225,114 & 67.4 & 690,707 & 3.06 & 217 & 3,183 \\
\hline 2008 & 473,220 & 232,348 & 67.1 & 705,568 & 3.12 & 249 & 2,834 \\
\hline 2009 & 662,629 & 216,600 & 75.4 & 879,229 & 3.89 & 257 & 3,421 \\
\hline
\end{tabular}

Source: Japan Dairy Council.

Table 5 shows the composition of demand in terms of types of visitors. Family visitors accounted for more than half of the total visitors with an increase in share from $50 \%$ to $61.7 \%$ in the past four years due to the rising popularity of this educational service while the share of those children who visited the farm from compulsory educational institutions as part of the school curriculum decreased from $26.4 \%$ to $19.1 \%$. 
Table 5: Composition of demand for farm education services.

\begin{tabular}{|c|c|c|c|c|c|c|c|c|}
\hline Items & $\begin{array}{c}\text { Nursery school } \\
\text { \& kindergarten }\end{array}$ & $\begin{array}{c}\text { Elementary } \\
\text { school }\end{array}$ & $\begin{array}{c}\text { Jr. high } \\
\text { school }\end{array}$ & $\begin{array}{c}\text { High school } \\
\text { or above }\end{array}$ & $\begin{array}{c}\text { Groups of } \\
\text { children }\end{array}$ & $\begin{array}{c}\text { Family \& } \\
\text { individuals }\end{array}$ & Others & Total \\
\hline$\%$ share (2006) & 8.1 & 16.2 & 10.2 & 7.3 & 8.2 & 50.0 & - & 100.0 \\
\hline$\%$ share (2009) & 6.3 & 13.4 & 5.6 & 4.0 & 7.1 & 61.7 & 2.0 & 100.0 \\
\hline $\begin{array}{c}\text { Average no. visitors } \\
\text { per group (2006) }\end{array}$ & 59.8 & 61.1 & 63.1 & 37.8 & 31.9 & 11.8 & - & 19.1 \\
\hline $\begin{array}{c}\text { Average no. visitors } \\
\text { per group (2009) }\end{array}$ & 58.1 & 56.8 & 44.7 & 26.6 & 29.7 & 4.7 & 4.2 & 7.0 \\
\hline \begin{tabular}{l} 
Source: Japan Dairy Council. \\
\hline
\end{tabular}
\end{tabular}

Thus, it is safe to say that there are two major sources of demand for visits to Educational Dairy Farms: schools and the population at large. The school demand gives children the opportunity to learn what actual dairy farmers do as basic education. Farmers also can have a stable educational demand because of farm experiences being implemented as part of the school curriculum. On the other hand, the family demand provides consumers and their children the opportunity to learn of life and work on dairy farms and increases opportunities for farmers to extend their educational services to the general public and gain revenue from that activity. Nevertheless, as shown in Table 5, family visitors arrive in groups much smaller than school visitors; therefore, as an economic activity, these small groups impose more labour input than the case of school demand and lower the efficiency of the service operation. This constraint causes the serious problem during the busiest summer season of how to allocate labour time between fodder and silage production, milk production and educational service provision. Consequently, this labour-allocation issue will become more serious when the number of family visitors increases further in the future. To address this trend, it is necessary to establish the viability of educational services.

\section{Results of survey of educational dairy farms}

\subsection{Experience service menus and price levying}

There exist a number of conditions to be solved for realization of viable educational services. Since no full scale survey of Educational Dairy Farms had been conducted, the author conducted a survey to gain an understanding of what and how existing educational services are implemented, problems related to educational activities and the operators' attitudes. The survey was sent to all 257 Educational Dairy Farm members by surface mail from October 1st to December $31^{\text {st }} 2009$. The response rate was $79.4 \%$ (204 farms).

Now let us examine results of the questionnaire survey from the viewpoint of what education services the Educational Dairy Farms provide. Table 6 shows tourism-related diversified activities undertaken by the Educational Dairy Farms. 
Table 6: Percentage of educational dairy farms implementing diversification.

\begin{tabular}{|c|c|c|c|c|}
\hline Activity & $\begin{array}{c}\text { Processing of } \\
\text { dairy products }\end{array}$ & Direct selling & Restaurant & Lodging facility \\
\hline \% of farms & 31.9 & 22.5 & 14.2 & 9.8 \\
\hline
\end{tabular}

Source: Questionnaire survey conducted jointly by the author and Japan Dairy Council (October to December in 2009). Sample size is 204.

Although processing of dairy products and direct selling were conducted by more than $30 \%$ and $20 \%$, respectively, of the Educational Dairy Farms, operating restaurants and lodging facilities were not common. Thus, it is safe to say that educational services were provided on a day-trip basis rather than as part of an overnight trip. This feature originates from the main aim of Educational Dairy Farms, which is to provide educational services as dairy farmers rather than tourism services as tourism ranches.

As shown in Table 7 there are two types of experience services: operationrelated and food/rural culture-related. It is easier for farmers to implement operation-related services because these services are provided in line with everyday operations on the farm. This is because the main activity of these farms is not tourism, but milk production. For this reason, operation-related services are more commonly implemented than culture-related services. An introductory explanation by the farmer and tour of the farmyard are necessary and important

Table 7: $\quad$ Offered Educational Dairy Farm services (individual menu).

\begin{tabular}{|c|c|c|c|c|c|c|c|}
\hline \multirow{2}{*}{ Type } & \multirow{2}{*}{ Menu } & \multicolumn{2}{|c|}{ Service provision } & \multicolumn{2}{|c|}{ Booking system } & \multicolumn{2}{|c|}{ Levying service charge } \\
\hline & & No. farms & $\%$ farms & No. farms & $\%$ farms & No. farms & $\%$ farms \\
\hline \multirow{8}{*}{$\begin{array}{c}\text { Farm- } \\
\text { operation } \\
\text { experiences }\end{array}$} & Lecture by farmer & 185 & 90.7 & 185 & 100.0 & 61 & 33.0 \\
\hline & Milking & 156 & 76.5 & 130 & 83.3 & 92 & 59.0 \\
\hline & Feeding & 154 & 75.5 & 121 & 78.6 & 61 & 39.6 \\
\hline & Giving bottle to calves & 143 & 70.1 & 119 & 83.2 & 64 & 44.8 \\
\hline & Cleaning barn & 112 & 54.9 & 86 & 35.0 & 35 & 31.3 \\
\hline & Brushing animals & 95 & 46.6 & 75 & 78.9 & 34 & 35.8 \\
\hline & Field work & 68 & 33.3 & 51 & 75.0 & 19 & 27.9 \\
\hline & Tour of farmyard & 183 & 89.7 & 122 & 66.7 & 42 & 23.0 \\
\hline \multirow{6}{*}{$\begin{array}{c}\text { Food/ rural } \\
\text { cultural } \\
\text { experiences }\end{array}$} & Horseback riding & 33 & 16.2 & 19 & 57.6 & 24 & 72.7 \\
\hline & Butter making & 133 & 65.2 & 107 & 80.5 & 104 & 78.2 \\
\hline & Cheese making & 37 & 18.1 & 32 & 86.5 & 29 & 78.4 \\
\hline & Ice cream making & 54 & 26.5 & 75 & 138.9 & 42 & 77.8 \\
\hline & Ham/sausage making & 68 & 33.3 & 13 & 19.1 & 19 & 27.9 \\
\hline & Shearing sheep & 15 & 7.4 & 9 & 60.0 & 5 & 33.3 \\
\hline
\end{tabular}

Source: Data are the same as for Table 6. 
for better results from the farm visit. Milking, feeding and bottling calves are the three most common operation-related services offered. In contrast, food/rural culture-related services are less commonly practiced than operation-related ones. Butter making and ice cream making are the two most popular items on cultural menus. Data shown on Table 7 indicate a problem, which is the low ratio of price levying for services in general and especially for operation-related services. Put differently, many services are offered free of charge without any compensation. Farmers must prepare to offer these services and to set aside their jobs for visitors, which mean that farmer's opportunity cost is required for the provision of these services. Compensation must be received for this opportunity cost for the sustainable development of the Educational Dairy Farms (Ohe [6]).

The case of set menu services is shown in Table 8. Components of a set menu consist of a combination of operation-related and culture-related services. A large portion of operators that provided a set menu had a booking system for reservations from visitors so that they could coordinate their schedule between the daily farm operation and farm visit. The ratio of price levying is higher in the case of the most common menu, which is Set menu 1. In this sense, having a set menu will be effective toward the viable educational services.

Table 8: $\quad$ Offered Educational Dairy Farm services (set menu).

\begin{tabular}{|c|c|c|c|c|c|c|}
\hline \multirow{2}{*}{ Type } & \multicolumn{2}{|c|}{ Service provision } & \multicolumn{2}{c|}{ Booking system } & \multicolumn{2}{c|}{ Levying service charge } \\
\cline { 2 - 8 } & No. farms & $\%$ farms & No. farms & \% farms & No. farms & \% farms \\
\hline Set menu 1 & 101 & 49.5 & 92 & 91.1 & 85 & 84.2 \\
\hline Set menu 2 & 48 & 23.5 & 42 & 87.5 & 42 & 87.5 \\
\hline Set menu 3 & 26 & 12.7 & 22 & 84.6 & 21 & 80.8 \\
\hline Set menu 4 & 6 & 2.9 & 5 & 83.3 & 5 & 83.3 \\
\hline Set menu 5 & 1 & 0.5 & 1 & 100.0 & 1 & 100.0 \\
\hline
\end{tabular}

Source : Data are the same as for Table 6.

\subsection{Attitudes of operators of the Educational Dairy Farm}

Now let us examine here attitudes of operators of the Educational Dairy Farms. First, as the reasons for starting educational services, over $40 \%$ of operators answered that they wanted to let people know what dairy farmers do to gain public understanding (Table 9). The second reason was that operators started as a community service in connection with local schools. These two major reasons are based on non-economic motivations of operators who wanted to do something for society and for the local community. In contrast, economic reasons, such as an income source and extension of farm activity, accounted for only $12.3 \%$ of operators.

Regarding areas targeted in offering educational experience services, more than half of operators targeted visitors from their neighbouring municipalities 
while one fourth of operators did not set any limitation on the area targeted. The wider the target area is, the more visitors' operators can accept; therefore, the target area indicates the market area that operators assume. Thus, the majority of operators did not assume their educational activity as nationwide but as locally limited.

Table 9: Reasons for starting educational activity.

\begin{tabular}{|c|c|c|}
\hline Items & Percentage & Sample size \\
\hline Letting people know farm job & 43.1 & 88 \\
\hline Community service & 23.5 & 48 \\
\hline Exchange with people & 11.8 & 24 \\
\hline Extension of activity domain & 7.4 & 15 \\
\hline Income source & 4.9 & 10 \\
\hline Other & 7.4 & 15 \\
\hline No response & 2.0 & 4 \\
\hline Total & 100.0 & 204 \\
\hline
\end{tabular}

Source: Data are the same as for Table 6.

Changes in operators' consciousness that occurred after starting the activity of the Educational Dairy Farms are shown in Table 10. Responses were given on a scale of one to five, with five being the most favourable response. As can be easily imagined from the reasons for starting this activity as discussed above, non-economic aspects were highly evaluated. Beginning with the highest score, exchange with people, a new role for dairy farming, value of local resources, self-confidence and local pride, connection with the local community, teaching and extension of their network beyond local boundaries were highly evaluated by scores greater than 4.0 followed the discovery of material for educational activities, which received a score of 4.0. These scores indicated that operators positively evaluated these aspects. In contrast, economic aspects, such as a means of marketing, listed in the table as 'direct selling of dairy products,' and an income source, were given lower scores of 3.0 or less, meaning that feelings on these aspects were either neutral or negative. These answers indicate that operators gained quite positive rewards in terms of non-economic aspects although they did not gain economic benefits from educational services. This is because direct contact with children and people in the farmyard brings a new enjoyment and raises operators' self-esteem toward their jobs and the local community through conducting the educational activity. In this respect, the effects of learning by doing are observed not only for visitors, but also for the operators themselves as well. These effects are not easy for ordinary dairy farmers to experience unless they host visitors in the farmyard. This is the significance of the educational activity for operators. 
Table 10: Changes in consciousness after starting an Educational Dairy Farm (EDF) (multiple answers).

\begin{tabular}{|c|c|c|}
\hline Items & Evaluated point & Sample size \\
\hline Exchange with people & 4.5 & 195 \\
\hline A new role & 4.4 & 195 \\
\hline Value of local resources & 4.4 & 190 \\
\hline Self-confidence/local pride & 4.3 & 191 \\
\hline Connection to local community & 4.3 & 193 \\
\hline Teaching & 4.3 & 189 \\
\hline Extension of network beyond local boundary & 4.1 & 192 \\
\hline Discovery of material for EDF services & 4.0 & 186 \\
\hline New viable activity & 3.0 & 187 \\
\hline Income source & 2.9 & 181 \\
\hline Direct selling of dairy products & 2.9 & 61 \\
\hline Nothing in particular & 2.0 & \\
\hline
\end{tabular}

Source: Same as for Table 6. Responses were given on a scale of 1 to 5 , with 5 being the most favorable response.

Now, let us look at the question of how operators currently position their educational activity within the whole farm activity and how they envision that activity in the future. Table 11 contrasts the present attitudes toward the Educational Dairy Farm activity with future intentions. Among the present

Table 11: Attitudes toward educational experience services (present and future).

\begin{tabular}{|c|c|c|c|c|}
\hline \multirow{2}{*}{ Items } & \multicolumn{2}{|c|}{ Present } & \multicolumn{2}{c|}{ Future } \\
\cline { 2 - 5 } & Percentage & Sample size & Percentage & Sample size \\
\hline Volunteer & 28.4 & 58 & 17.2 & 35 \\
\hline Cost covering & 31.9 & 65 & 24.0 & 49 \\
\hline Measure of marketing & 7.4 & 15 & 23.0 & 47 \\
\hline Aiming at viable activity & 16.7 & 34 & 24.0 & 49 \\
\hline Nothing in particular & 7.8 & 16 & - & \\
\hline Decrease/quit & - & - & 1.0 & 2 \\
\hline Don't know & - & - & 2.5 & 5 \\
\hline Others & 5.4 & 11 & 5.4 & 11 \\
\hline No answer & 2.5 & 5 & 2.9 & 6 \\
\hline Total & 100.0 & 204 & 100.0 & 204 \\
\hline
\end{tabular}

Source: Data are the same as for Table 6. 
attitudes, 'cost covering' and 'volunteer' account for $60 \%$ of responses, which indicate that the respondent operators consider it as a non-profit activity or have no orientation toward economic viability of the educational experience services. On the other hand, those who expressed 'marketing' and 'aiming at viable activity' only accounted for one fourth of the total responses, and these respondents are supposed to have an orientation toward viable services. Now turning to future intentions, those with no orientation toward viability dropped to about $40 \%$, and nearly $50 \%$ of operators expressed their intention to seek viability. Thus, it is safe to say that many operators intend to establish viability of educational services in the long run. The author also considers that this direction is a necessary step to gain broad recognition of Educational Dairy Farms playing a new role in society because the value of gratis service is not respected and gives no incentive to raise the quality of service. To put it differently, the lack of economic viability in educational services can impede the sustainable development of these services and therefore should be rectified for sustainable development in the future.

\subsection{Text analysis of open-ended responses}

As the last part of the empirical examination, using the frequency of key words in the text of open-ended responses to an invitation of responders to write their thoughts regarding their experience or role in Educational Dairy Farms, I conducted a qualitative analysis of the responses (Table 12). Frequency of words and phrases that appeared in the text was counted. The left column in Table 12 lists positive responses in the order of frequency regarding their educational activity, which included the key words of 'joyful', 'meaning of life' and 'touching'. These responses specifically confirm the positive psychological effects on operators mentioned earlier in this chapter. Other frequently used keywords were 'experiences', 'children', 'life' and 'local area', which have a positive connotation in connection with the Educational Dairy Farms.

Table 12: Results of analysis of open-ended responses.

\begin{tabular}{|c|c|c|c|}
\hline \multicolumn{2}{|c|}{ Positive connotation } & \multicolumn{2}{c|}{ Negative connotation } \\
\hline Keywords & No. cases & Keywords & No. cases \\
\hline Educational dairy farm & 27 & Schools & 15 \\
\hline Joyful/purpose of life/touching & 27 & Tourism/leisure & 9 \\
\hline Experiences & 23 & Educational materials & 6 \\
\hline Children & 20 & Volunteer & 5 \\
\hline Life & 9 & Labour & 2 \\
\hline Local area & 5 & Problems & 2 \\
\hline
\end{tabular}

Source: 91 of the 204 survey responders (35.4\%) provided open-ended responses. No. of cases are overlapped. 
In short, from the text analysis it was revealed that the operators gained psychological satisfaction from the educational activities and also clarified issues that needed to be improved. Especially, a good relationship with schoolteachers is vital to realizing an effective farm visit.

In the right column, operators' opinions with negative connotations, which imply problems, were listed. The keyword 'schools' was often used in the context of frustration and dissatisfaction with teachers' ignorance and their low level of interest in the visit that typically led to students being poorly prepared for the farm visit. To address this issue, some of the operators suggested courses for teachers to raise consciousness of the meaning of the farm visit. The second most frequent keywords were 'tourism' and 'leisure', which emerged in the context of a skeptical attitude toward a tourism and leisure orientation or opposition against the evolution toward a commercial tourism ranch from an Educational Dairy Farm. Operators who expressed this opinion were those who thought that the educational activity should be practiced gratis because their main mission was to produce milk as food, not to entertain visitors. On the other hand, the keyword 'volunteer' was used in the context of an opinion that urged the necessity for no longer providing a volunteer activity and that costs should be levied for experience services. However, levying a service fee does not mean that the Educational Dairy Farms would become strictly tourism ranches. The differences between the two opposite opinions, that is, the desire to perform services gratis in contrast with the desire to charge a service fee, come from the differences in how an operator evaluated the significance of the social role and responsibility for experience services. Thus, to narrow the gap between the two attitudes, something should be done to raise operators' consciousness toward undertaking a viable educational activity.

Educational materials, which were developed and distributed by the Japan Dairy Council, were mentioned in the context of gratitude for their good quality and the number of materials on one hand and complaints that there were too many materials to use effectively on the other hand. Among other comments, a few operators expressed the problem of a labour shortage because educational services are labour intensive, which is consistent with the increase in the number of visitors quantitatively and qualitatively as mentioned earlier.

\section{Conclusion}

This paper empirically studied the educational function in agriculture by focusing on the current situations and issues regarding educational tourism in agriculture. Main points investigated were as follows.

First, we characterized the features of educational tourism in Japan by focusing on school trips and pointed out an experience-oriented trend. Although educational tourism in agriculture accounts for a small portion of school trip programs, the stable annual demand that is a distinct characteristic of school trips is an attractive feature to induce agricultural areas to develop school trip programs. 
Second, from the questionnaire survey of operators of Educational Dairy Farms in Japan, it is safe to say that the educational function in agriculture generates educational effects that enable not only consumers to learn of the close relationship between food and life and the rural heritage, but that also enable operators themselves to learn a new role in society and to utilize unused farm resources that yields a positive psychological reward. Thus, the educational function in agriculture will eventually lead to more efficient utilization of farm resources.

Third, since the problem of educational services is that educational services per se are not yet economically viable, it is necessary to establish the viability of these educational services. To this end, the first step is to enhance the public understanding and recognition of the educational function in agriculture. It should be noted that levying a service fee does not instantly mean that Educational Dairy Farms will become tourism ranches. Thus, it is necessary to establish a balance between the educational function and economic viability to develop a new role for agriculture in society. Keeping this in mind, cohesive local action is needed to explore educational tourism in agriculture. Therefore, support measures should be undertaken to achieve this.

\section{Acknowledgement}

This study was funded by the Grants-in-Aid for Scientific Research, no. 20248024, Japan Society for the Promotion of Science (JSPS).

\section{References}

[1] Garrett, R., Making an ecological place: city farm Byker (Newcastle). Bulletin Environmental Education, 184, pp.4-7, 1986.

[2] Graham, B., The work of farming and countryside education (FACE). $J$. Royal Agricultural Society of England, 165, pp.1-8, 2004.

[3] Regione Emilia-Romagna, Fattorie Didattiche dell' Emilia-Romagna: Guida ai Percorsi Didattici nelle Aziende Agricole. Regione Emilia-Romagna: Bologna, 2005.

[4] Ohe, Y., Evaluating jointness of multifunctional agriculture: the educational function of dairy farming in Japan, Environmental Economics and Investment Assessment, ed. K. Aravossis, C.A. Brebbia, E. Kakaras \& A.G. Kungolos, WIT Press: Southampton, pp.337-346, 2006.

[5] Ohe, Y., Emerging environmental and educational service of dairy farming in Japan: dilemma or opportunity? Ecosystems and Sustainable Development VI, ed. E. Tiezzi, J.C. Marques, C.A. Brebbia \& S.E. Jørgensen, WIT Press: Southampton, pp.425-436, 2007.

[6] Ohe, Y., Evaluating Internalization of Multifunctionality by Farm Diversification: Evidence from Educational Dairy Farms in Japan. $J$. Environ. Manage. 92, pp.886-891, 2011. 